\title{
MIGRATION COMPETITION IN ENLARGED EUROPEAN UNION: A THEORETICAL MODEL
}

\author{
Pierpaolo Giannoccolo \\ Assistant Professor at University of Bologna, Department of Economics, \\ Visiting professor at Preg - UMR 7176 - Ecole Polytechnique \\ E-mail address pierpaolo.giannoccolo@unibo.it
}

\begin{abstract}
$\underline{A B S T R A C T}$
In this article, we propose a theoretical model which help us to define two possible settings where the European "migration competition" could be analysed. First, we analyse the scenario in which there are two regions: a receiving country and a net sending country. In this scenario we introduce the possibility for each country to increase, by investing resources, the level of integration between countries which consequently reduces the level of migration costs. Thus it is possible to capture the receiving country's trade off between investing resources in order to attract foreign high skilled workers or investing on educational incentives for his citizens. Second, we analyse the scenario in which there are three regions. Starting from the first scenario's framework, we could analyse either the case in which a new country is able to intercept a significant quota of the flow of skilled migrants, either the effect of migration competition between the two regions in order to attract the skilled workers of the sending country. In both case analysed, the presence of a central authority which coordinates the migration and fiscal policies is determinant to obtain better results.
\end{abstract}

Keywords: Brain Drain, Migration policies, Human Capital, High skilled workers.

JEL Classification: F22, I23, J24, P16 


\section{INTRODUCTION}

The enlarged European Union (EU hereafter) changed migration incentives, and therefore many European countries are either alarmed about preserving their investment in human capital, either encouraged to implement policies to attract skilled personal from neighbours. In this article, we propose an extension of Andersen (2005) in order to describe a framework close to this new EU scenario where it is necessary to define a new Brain Drain (BD hereafter) typology specific to the European context where the migration policies can be used as a "new policy tool" by regions. In particular, we analyse two possible settings where the European "migration competition" could be analysed.

Analysing the migration policies of the EU we identify a dual approach: a) internal migration of EU nationals has been harmonized at the EU level, becoming essentially free by 2014 for the whole EU27. b) External migration rules are not harmonized as they generally fall within the responsibility of each individual member state. Furthermore, from 2006 policies relating to the free movement of workers of the EU-15 states could be classified into three categories: i) Keeping the restrictions in place for at least three more years: Austria, Germany; ii) Lifting the restrictions gradually, within the next three years: Belgium, Denmark, France, Luxembourg, the Netherlands; iii) Keeping labour markets open/removing restrictions: Finland, Greece, Ireland, Portugal, Spain, Sweden, Italy, United Kingdom; All countries except Finland have opted for transition periods for workers from Bulgaria and Romania.

If we concentrate our analysis on the migration flow from and in the EU, it is possible identify three main groups of regions. First, there are the regions which thanks their higher productivity of the labour (i.e. higher level of technology, etc.) attract from the other countries skilled workers. These ones are defined in this work as receiving countries $(f f)^{1}$ and are U.S.A., Canada, U.K., France, Sweden, etc. Second, there are regions with lower productivity and high flows of skilled worker which migrate inside the EU and where the mobility of their citizens is increasing thanks their membership to the EU and specific migration policies. These ones are defined in this work as sending countries $(h)$ and are (in particular, eastern European countries. Finally, there are regions characterized by similar productivity of the labour and where the mobility is free of institutional constraints (the former EU member) which attract skilled from the sending regions and provide skilled to the receiving ones. These ones are defined in this work as sending and receiving countries $(f)$ and in some case suffer of a net BD like Finland, Germany and Italy.

In this paper we develop a model which incorporates the interactions between these three groups. In particular, the first specification of the model defines a framework with two regions (group of regions) with different labour productivity. One is a net receiving country and the other one is a net sending country. In this scenario we introduce the possibility for the receiving country to increase, by investing resources, the level of integration between countries which consequently reduces the level of migration costs. Thus it is possible to

\footnotetext{
${ }^{1}$ In general, the BD phenomenon is very highly concentrated in only five countries which attract $80 \%$ of foreign students of OECD area: United States (34\%), United Kingdom (16\%), Germany (13\%), France (11\%), and Australia (8\%).
} 
capture the receiving country's trade off between investing resources in order to attract foreign high skilled workers or investing on educational incentives for his citizens.

Furthermore, the second specification of the model defines a framework with three regions (group of regions): the receiving region ( $f f$ ) which is able, thanks the implementation of specific migration policies, to intercept a significant quota of the flow of skilled migrants, the sending regions $(h)$ which has negative flow of skilled and the receiving and sending country $(f)$ which, from one side implement policies to compensate the migration policies of ff in order to stop his $\mathrm{BD}$, and from the other side implements migration policies to attract skilled from $h$.

In both scenarios analysed in this paper, the presence of migration policies has an important impact on the redistributive policies (between high skilled and low skilled citizens) and on the publicly educational policies (investment in education, subsidies, etc.). In particular, in absence of coordination we assist to a lower provision of the public good education (in literature is the "rice to bottom") and lower redistribution policies. Furthermore, if we introduce three levels of interaction between the three groups identified in the model, the migration policies are used as instrument for a migration competition between the receiving and sending and receiving countries. This competition has the effect to accelerate the rice to bottom. Initiative like the European Commission target of the 3\% of the GDP as a minimum level of investment in $\mathrm{R} \& \mathrm{D}$ are a possible answer to avoid these problems

The structure of the paper is the following: in the section two we define the statement of the model and we define the how the migration policies effected directly the migration decision and indirectly the educational decisions of the agents and we overview the European migration policies. In sections third and fourth section we solve the model in the two regions and three regions specification. Finally, the fifth section analyse the results obtained and gives the conclusions. 


\section{THE MODEL}

In this model we analyse a world with $K$ states. In each region, there exist two typologies of workers: skilled and unskilled. To be skilled agents requires education which implies various costs. We describe a two periods overlapping generations model in which young agents acquire education, working as skilled when old, or work in both periods as unskilled. The population is normalized to unity and is assumed stationary.

Agents are heterogeneous in two characteristics $(i, j): j$ which indexes attributes related to skill acquisition, and $i$ which indexes attributes related to the attitude to migrate (see below). Let us assume that $j \in J \equiv[0,1]$ and denote the density of the population across characteristics $j$ by $f(j)$. Each individual $(i, j)$ is characterized by the (semi-indirect) utility function $U(i, j)=V(i, j)-a e(j)-b c(i)$. Where $V(i, j)$ is the present value of income, $e(j)$ is the utility costs of acquiring education ( $a=0$ if no education is acquired as young, and $a=1$ if educated), and $c(i)$ the utility costs of migrating ( $b=0$ if non-migrant, and $b=1$ if migrant).

Let us assume that in this economy the only productive factor is the labour (skilled and unskilled). Furthermore, the demand for the two types of labour in region $k$, is given by $L_{k}^{s}\left(w_{k}^{s}, w_{k}^{u}, x\right), \quad L_{k}^{u}\left(w_{k}^{s}, w_{k}^{u}, x\right)$ where: $\partial L_{k}^{s} / \partial w_{k}^{s}, \partial L_{k}^{u} / \partial w_{k}^{u}<0 ; x$ contains the other important elements which influence the labour demand and assumed constant in this model; $w_{k}^{s}$ and $w_{k}^{u}$ are the wages of skilled and unskilled.

Furthermore, we assume that in each region $k$ the government taxes labour income to finance a given level of public consumption, education and education subsidies ${ }^{2}$. The tax rate on unskilled is symbolized by $t_{k}^{s}$ and $t_{k}^{u}$. Moreover, by assuming that $t_{k}^{s}>t_{k}^{u}$ if $w_{k}^{s}>w_{k}^{u}$ these two variables capture the progression in the taxation and so all possible redistribution policies. See below furthermore details on the government's policies.

\subsection{Education}

A young agent chooses to be educated if $\left(s_{k}-e\left(j_{k}\right)\right)+\frac{w_{k}^{s}\left(1-t_{k}^{s}\right)}{1+r} \geq w_{k}^{u}\left(1-t_{k}^{u}\right)+\frac{w_{k}^{u}\left(1-t_{k}^{u}\right)}{1+r}$, where $s_{k}$ is the educational cost financed by government $k$ (i.e. grant to students, investment in public education, etc.) and $e(j)$ denotes utility costs of acquiring skills (effort, ability etc). Let us assume that agents are ordered such that $e(j)$ is increasing in $j$.

\footnotetext{
${ }^{2}$ In Austria, Denmark, Finland, Greece and Poland the totality of the tertiary education is provided by government Moreover in Belgium, Czech Republic, France, Germany, Ireland Italy, Portugal, Slovak Republic and Sweden we have al least the $80 \%$ of tertiary education publicly .financed. Finally, In Hungary, Netherlands, Spain and United Kingdom the share is from 70 to $80 \%$ (OECD 2004).
} 
Finally, $r$ denotes the shadow price of borrowing in the capital market. It follows that the marginal worker which decides to acquire skills, $j_{k}^{*} \in J$ is given by the condition

$$
\left(s_{k}-e\left(j_{k}^{*}\right)\right)+\frac{w_{k}^{s}\left(1-t_{k}^{s}\right)}{1+r}=w_{k}^{u}\left(1-t_{k}^{u}\right)+\frac{w_{k}^{u}\left(1-t_{k}^{u}\right)}{1+r} .
$$

Therefore, $\lambda_{k}=\int_{0}^{j_{k}^{*}} f(j) d j$, defines the fraction of the population which becomes educated and $1-\lambda_{k}$ the fraction of unskilled workers. Let us assume that exist an interior solution.

Note that the government is able to influence the private decision to be educated either by implementing educational policies by increasing/decreasing the provision of the public good education $\left(\partial \lambda_{k} / \partial s_{k}>0\right)$, either by implementing taxation policies $\left(\partial \lambda_{k} / \partial t_{k}^{u}>0\right.$ and $\left.\partial \lambda_{k} / \partial t_{k}^{s}<0\right)$.

\subsection{Migration}

Let us assume that only the old skilled workers are entitled to migrate ${ }^{3}$. An old agent does not migrate if $w_{k}^{s}\left(1-t_{k}^{s}\right) \geq w_{f}^{s}\left(1-t_{f}^{s}\right)-c\left(i_{k}, m\right)$, where $w_{f}^{s}\left(1-t_{f}^{s}\right)$ shows the after tax income available in a foreign country and $c\left(i_{k}, m\right)$ gives the utility loss of migration (tangible and intangible costs, language adaptation, integration, etc.), where the variable $m$ is an indicator for integration between countries. Let us assume that $\partial c / \partial m<0$, i.e. the higher $m$ the more internationally integrated the region, and the utility costs of migration are assumed to be non-increasing in this indicator for all individuals. Let us define $h\left(i_{k} \mid j_{k} \leq j_{k}^{*}\right)$ the density for characteristics $i$ conditional on the individual choosing to become educated, that this function is increasing in $i$ and let us assume that the marginally educated is not the marginal migrant $\left(i_{k}^{*}<j_{k}^{*}\right)$. It follows that the marginal skilled worker which decides to stay at home is given by the condition

$$
w_{k}^{s}\left(1-t_{k}^{s}\right)=w_{f}^{s}\left(1-t_{f}^{s}\right)-c\left(i_{k}^{*}, m\right)
$$

It is equivalent to assume that the migration cost for the unskilled are too high and not compensate the eventually higher wage that he could receive migrating abroad.

Therefore, $\mu_{k}=\int_{0}^{i_{k}^{*}} h\left(i_{k} \mid j_{k} \leq j_{k}^{*}\right) d j$, defines the fraction of the skilled which remain at home and $1-\mu_{k}$ the fraction of migrants.

\footnotetext{
${ }^{3}$ It is equivalent to assume that the migration cost for the unskilled are too high and not compensate the eventually higher wage that he could receive migrating abroad. In this way we can focus our analysis on the skilled migration.
} 
Finally, let us define the policies migration. Let us assume that $m$ is function of the different migration policies of the regions ${ }^{4}$.

$$
m=m_{0}+\sum_{1}^{K} m_{k}
$$

Note that the government is able to influence the individual decision to migrate either by implementing migration policies by increasing/decreasing the investment in integration of migrants $\left(\partial \mu_{k} / \partial m<0\right)$, either by implementing taxation policies $\left(\partial \mu_{k} / \partial t_{k}^{s}<0, \partial \mu_{k} / \partial t_{f}^{s}>0\right)$.

In general, the migration policies often integrate by fiscal policies, focus on the individual motivation to migrate by generating individual incentives or by decreasing the migration costs. Let us analyse in the following paragraphs some examples of policies implemented in Europe which is included in $m$.

Because, the lack of knowledge of the local language is a problem, particularly for less widely used languages and can hamper the social integration, some countries like Greece and Germany, provide easier access to fast-track language courses. Likewise, in some countries, e.g. Luxembourg and Finland, special language and cultural support is offered to accompanying children both in the foreign and mother tongues.

Furthermore, some policies provided incentives and facilitations to the Researcher's family: For researchers moving with their family, the partner's career, children's education or daycare, suitable accommodation and obligations remaining in the home country (such as rent or mortgage payments, or care of elderly parents) may all pose barriers for the mobility. Furthermore, in some countries, e.g. Finland and Greece, the researcher's family is taken into account when granting funding for stays abroad. Finally, in Finland and Sweden, all children have the right by law to day-care.

Moreover, some policies are directly addressed to the researchers and theirs career by the provision of incentives and facilitation. There are several examples of policies that help researchers to avoid several problems (access to information about rules and regulations, administrative procedures, etc.). For instance in Belgium, replacement costs for researchers on sabbaticals are covered, furthermore, in a Greek research institute, to integrate foreign scientists into the local research environment is used the method to encourage their participation in the decision making of the host institution. Finally, in certain countries, foreign researchers recruited to a university may have transition periods, during which they may teach in a foreign language, before being obliged to teach in the local language.

Furthermore, there are several examples of grant and scholarships, tax and salaries and specific marketing and recruiting policies used by several European regions ad specific instrument to attract skilled workers 5 .

\footnotetext{
${ }^{4}$ By assumption, these migration policies increase only the mobility of the skilled workers.

${ }^{5}$ Let see the conclusion for specific examples of these policies.
} 


\section{TWO REGIONS' MARKET EQUILIBRIUM}

Let us assume that there exist two regions ${ }^{6}$ Let us define $h$ the net-sending region and $f$ the net-receiving country. According the previous sections, the labour market equilibrium is $L_{k}^{s}\left(w_{k}^{s}, w_{k}^{u}, x\right)=\mu_{k} \lambda_{k}$ for the net-sending regions, $L_{f}^{s}\left(w_{f}^{s}, w_{f}^{u}, x\right)=\left(1-\mu_{k}\right) \lambda_{k}+\lambda_{f}$ for the pure receiving country and $L_{k}^{u}\left(w_{k}^{s}, w_{k}^{u}, x\right)=2\left(1-\lambda_{k}\right)$, with $k=h, f$.

Furthermore, we define the public budget constraint of the two regions

$$
\begin{aligned}
& \lambda_{h} \mu_{h} w_{h}^{s} t_{h}^{s}+2\left(1-\lambda_{h}\right) w_{h}^{u} t_{h}^{u}=g_{h}+\lambda_{h} s_{h}+\vartheta m_{h} \\
& \left(\lambda_{h}\left(1-\mu_{h}\right)+\lambda_{f}\right) w_{f}^{s} t_{f}^{s}+2\left(1-\lambda_{f}\right) w_{f}^{u} t_{f}^{u}=g_{f}+\lambda_{f} s_{f}+\vartheta m_{f}
\end{aligned}
$$

The LHS gives the revenue from taxing skilled and unskilled workers, and the RHS the expenditures to public consumption (exogenous by assumption), and the educational subsidies/expenditures (endogenous) for the fraction of the population becoming educated. It is straightforward that the receiving region $f$ is able to tax an higher basin of skilled workers thanks migration flows and increase the available resources that could be used to implement educational, redistributive and migration policies.

\section{1 increasing in the mobility - Brain Drain policies}

Let us analyse the effect of migration policies inside this economy with two regions. Let us assume that the receiving region implement new migration policies ${ }^{7}$ as we show in the previous section.

To analyse better the effect of these policies, let us study a given stationary equilibrium $\left\{w_{k}^{s}, w_{k}^{u}, t_{k}^{s}, t_{k}^{u}, \lambda_{k}, \mu_{k}\right\}$ with $k=h, f$ and where $0<\lambda_{k}, \mu_{k}<1$.

Furthermore, we assume that the region $f$ increases the integration by increasing $m_{k}$ such that $d c=\frac{\partial c}{\partial m} \frac{\partial m}{\partial m_{k}}<0$, the costs of migration are decreasing for all the skilled workers.

Let us now considered which policy changes are needed to maintain unchanged migration (unchanged $\mu_{k}$ ) and unchanged educational incentives (unchanged $\lambda_{k}$ ). This analysis help us to identify the relationships between the migration policies and the educational and redistributive policies. Moreover, by studying the model in a stable equilibrium, we simplify the analysis because if migration flows are unaffected so will the supply of both skilled and unskilled workers, and therefore the wage rates will be unaffected.

${ }^{6}$ The analysis could be extended to two groups of region with the same productivity characteristics inside the groups i.e. the former EU and the new entrants.

${ }^{7}$ This assumption is a strong innovation respect Andersen (2005) where the migration barriers are considered exogenous variables and not possible tool of government's policy. 
Let us study the condition to have in region $h$, unchanged education incentives (equation 6), unchanged migration incentives (equation 7) and budget balance constraint applied by analysing respectively equations (1), (2) and (4).

$$
\begin{aligned}
& \frac{\partial t_{h}^{s}}{\partial m}=\frac{w_{f}^{s}}{w_{k}^{s}}\left(\frac{\partial t_{f}^{s}}{\partial m}\right)+\frac{1}{w_{k}^{s}}\left(\frac{\partial c\left(i_{k}^{*}, m\right)}{\partial m}\right) \\
& \frac{\partial s_{h}}{\partial m}=\frac{w_{h}^{s}}{1+r}\left(\frac{\partial t_{h}^{s}}{\partial m}\right)-\frac{(2+r) w_{h}^{u}}{1+r}\left(\frac{\partial t_{h}^{u}}{\partial m}\right) . \\
& \lambda_{h} \mu_{h} w_{h}^{s}\left(\frac{\partial t_{h}^{s}}{\partial m}\right)+2\left(1-\lambda_{h}\right) w_{h}^{u}\left(\frac{\partial t_{h}^{u}}{\partial m}\right)=\lambda_{h}\left(\frac{\partial s_{h}}{\partial m}\right)
\end{aligned}
$$

Therefore, solving the system given by equation (6) -(7), we derive

$$
\left\{\begin{array}{l}
\frac{\partial t_{h}^{s}}{\partial m}=\frac{w_{f}^{s}}{w_{k}^{s}}\left(\frac{\partial t_{f}^{s}}{\partial m}\right)+\frac{1}{w_{k}^{s}}\left(\frac{\partial c\left(i_{k}^{*}, m\right)}{\partial m}\right) \\
\frac{\partial s_{h}}{\partial m}=\frac{w_{h}^{s}}{1+r}\left(\frac{\partial t_{h}^{s}}{\partial m}\right)-\frac{(2+r) w_{h}^{u}}{1+r}\left(\frac{\partial t_{h}^{u}}{\partial m}\right) \\
\frac{\partial t_{h}^{u}}{\partial m}=\frac{\lambda_{h}\left(1-(1+r) \mu_{h}\right)}{\left(2(1+r)-r \lambda_{h}\right)} \frac{w_{h}^{s}}{w_{h}^{u}}\left(\frac{\partial t_{h}^{s}}{\partial m}\right)
\end{array}\right.
$$

or, computing

$$
\left\{\begin{array}{l}
\frac{\partial t_{h}^{s}}{\partial m}=\frac{w_{f}^{s}}{w_{k}^{s}}\left(\frac{\partial t_{f}^{s}}{\partial m}\right)+\frac{1}{w_{k}^{s}}\left(\frac{\partial c\left(i_{k}^{*}, m\right)}{\partial m}\right) \\
\frac{\partial s_{h}}{\partial m}=\frac{1}{1+r}\left(1-\frac{(2+r)\left(1-(1+r) \mu_{h}\right) \lambda_{h}}{\left(2(1+r)-r \lambda_{h}\right)}\right)\left(w_{f}^{s} \frac{\partial t_{f}^{s}}{\partial m}+\frac{\partial c\left(i_{k}^{*}, m\right)}{\partial m}\right) \\
\frac{\partial t_{h}^{u}}{\partial m}=\frac{\lambda_{h}\left(1-(1+r) \mu_{h}\right)}{\left(2(1+r)-r \lambda_{h}\right)} \frac{1}{w_{h}^{u}}\left(w_{f}^{s}\left(\frac{\partial t_{f}^{s}}{\partial m}\right)+\left(\frac{\partial c\left(i_{k}^{*}, m\right)}{\partial m}\right)\right)
\end{array}\right.
$$

Let us analyse the Balance Constraint of region $f$ and the unchanged education incentives. The policies of region $h$ maintain unchanged the migration and, in this section, we assume that the fiscal policies are not used by region $\mathrm{f}$ to attract skilled. 


$$
\begin{aligned}
& \left(\lambda_{h}\left(1-\mu_{h}\right)+\lambda_{f}\right) w_{f}^{s}\left(\frac{\partial t_{f}^{s}}{\partial m}\right)+2\left(1-\lambda_{f}\right) w_{f}^{u}\left(\frac{\partial t_{f}^{u}}{\partial m}\right)=\lambda_{f}\left(\frac{\partial s_{f}}{\partial m}\right)+\vartheta \\
& \frac{\partial s_{f}}{\partial m}=\frac{w_{f}^{s}}{1+r}\left(\frac{\partial t_{f}^{s}}{\partial m}\right)-\frac{(2+r) w_{f}^{u}}{1+r}\left(\frac{\partial t_{f}^{u}}{\partial m}\right) .
\end{aligned}
$$

Therefore, solving the system

$$
\left\{\begin{array}{c}
\frac{\partial t_{f}^{s}}{\partial m}=\frac{-w_{f}^{u}\left(2+\frac{r \lambda_{f}}{1+r}\right)\left(\frac{\partial t_{f}^{u}}{\partial m}\right)+\vartheta}{w_{f}^{s}\left(\lambda_{h}\left(1-\mu_{h}\right)+\lambda_{f} \frac{r}{1+r}\right)} \\
\frac{\partial s_{f}}{\partial m}=\frac{w_{f}^{s}}{1+r}\left(\frac{\partial t_{f}^{s}}{\partial m}\right)-\frac{(2+r) w_{f}^{u}}{1+r}\left(\frac{\partial t_{f}^{u}}{\partial m}\right)
\end{array}\right.
$$

Let us study two possible scenario: a) Government of $f$ does not change the tax to educated and consequently the only policies implemented is the migration one; b) Government of $f$ does not change the tax to non-educated. And consequently the region is forced to increase the tax to the skilled workers.

Scenario a (only migration policies) $\frac{\partial t_{f}^{s}}{\partial m}=0$.

In the first case, by the equation (13), implies that

$$
\left\{\begin{array}{l}
\frac{\partial t_{f}^{s}}{\partial m}=0 \\
\frac{\partial t_{f}^{u}}{\partial m}=\frac{\vartheta}{w_{f}^{u}\left(2+\frac{r \lambda_{f}}{1+r}\right)}>0 \\
\frac{\partial s_{f}}{\partial m}=-\frac{(2+r)}{2(1+r) r \lambda_{f}} \vartheta<0
\end{array}\right.
$$

The government of $f$ compensates the increasing cost in migration policies (given by $\vartheta$ ) by increasing the taxation of .unskilled and by decreasing the provision of public education. In particular, higher is the quota of skilled workers of $f$, lower is the increasing in the unskilled taxation and the decreasing of publicly education.

Let us study in this scenario the region $h$ by studying the system (10) when $\frac{\partial t_{f}^{s}}{\partial m}=0$. 


$$
\left\{\begin{array}{l}
\frac{\partial t_{h}^{s}}{\partial m}=\frac{1}{w_{k}^{s}}\left(\frac{\partial c\left(i_{k}^{*}, m\right)}{\partial m}\right) \\
\frac{\partial s_{h}}{\partial m}=\frac{1}{1+r}\left(1-\frac{(2+r)\left(1-(1+r) \mu_{h}\right) \lambda_{h}}{\left(2(1+r)-r \lambda_{h}\right)}\right)\left(\frac{\partial c\left(i_{k}^{*}, m\right)}{\partial m}\right) \\
\frac{\partial t_{h}^{u}}{\partial m}=\frac{\lambda_{h}\left(1-(1+r) \mu_{h}\right)}{\left(2(1+r)-r \lambda_{h}\right)} \frac{1}{w_{h}^{u}}\left(\frac{\partial c\left(i_{k}^{*}, m\right)}{\partial m}\right)
\end{array}\right.
$$

These results are the same obtained by Andersen (2005). According to him let us study the sign of the three variables.

By definition, $\frac{\partial c\left(i_{k}^{*}, m\right)}{\partial m}<0$ then $\frac{\partial t_{h}^{s}}{\partial m}<0$. The sending region $h$, in order to compensate lower barriers to migration, has to decreasing the taxation of skilled workers.

Furthermore, the sign of the provision of the public good education is given by $\left(1-\frac{(2+r)\left(1-(1+r) \mu_{h}\right) \lambda_{h}}{\left(2(1+r)-r \lambda_{h}\right)}\right)$. In particular, if $\left(\frac{2}{(2+r)}-(1+r) \mu_{h}\right) \lambda_{h}<1$ (i.e. the initial level of migration and /or the quota of skilled is not too large) then lower barriers to migration imply $\frac{\partial s_{h}}{\partial m}<0$.

Finally, the sign of the tax to unskilled is given by $\frac{\lambda_{h}\left(1-(1+r) \mu_{h}\right)}{\left(2(1+r)-r \lambda_{h}\right)}$. In particular, the denominator is always positive, than if $\mu_{h}<\frac{1}{(1+r)}$ (i.e. the initial level of migration is not too large) then lower barriers to migration imply that $\frac{\partial t_{h}^{u}}{\partial m}>0$. Note that the more costly it is to acquire education (the higher $r$ ), the worse is the redistribution of resource to the unskilled.

Scenario b (migration policies and redistributive constraints) $\frac{\partial t_{f}^{u}}{\partial m}=0$.

In the second case, by the equation (13), implies that 


$$
\left\{\begin{array}{l}
\frac{\partial t_{f}^{s}}{\partial m}=\frac{\vartheta}{w_{f}^{s}\left(\lambda_{h}\left(1-\mu_{h}\right)+\lambda_{f} \frac{r}{1+r}\right)} \\
\frac{\partial t_{f}^{u}}{\partial m}=0 \\
\frac{\partial s_{f}}{\partial m}=\frac{\vartheta}{\left((1+r) \lambda_{h}\left(1-\mu_{h}\right)+r \lambda_{f}\right)}>0
\end{array}\right.
$$

The government of $f$ compensates the increasing cost in migration policies by increasing the taxation of .skilled and by increasing the provision of public education. In particular, higher is the quota of skilled workers in $f$ (natives and foreign), lower is the increasing in the skilled taxation and the increasing of publicly education.

Let us study in this scenario the region $h$ by studying the system (10) when $\frac{\partial t_{f}^{s}}{\partial m} \neq 0$.

$$
\left\{\begin{array}{l}
\frac{\partial t_{h}^{s}}{\partial m}=\frac{1}{w_{k}^{s}} \frac{\vartheta}{\left(\lambda_{h}\left(1-\mu_{h}\right)+\lambda_{f} \frac{r}{1+r}\right)}+\frac{1}{w_{k}^{s}}\left(\frac{\partial c\left(i_{k}^{*}, m\right)}{\partial m}\right) \\
\frac{\partial s_{h}}{\partial m}=\frac{1}{1+r}\left(1-\frac{(2+r)\left(1-(1+r) \mu_{h}\right) \lambda_{h}}{\left(2(1+r)-r \lambda_{h}\right)}\right)\left(\frac{\vartheta}{\left(\lambda_{h}\left(1-\mu_{h}\right)+\lambda_{f} \frac{r}{1+r}\right)}+\frac{\partial c\left(i_{k}^{*}, m\right)}{\partial m}\right) \\
\frac{\partial t_{h}^{u}}{\partial m}=\frac{\lambda_{h}\left(1-(1+r) \mu_{h}\right)}{\left(2(1+r)-r \lambda_{h}\right)} \frac{1}{w_{h}^{u}}\left(\left(\frac{\vartheta}{\left(\lambda_{h}\left(1-\mu_{h}\right)+\lambda_{f} \frac{r}{1+r}\right)}\right)+\left(\frac{\partial c\left(i_{k}^{*}, m\right)}{\partial m}\right)\right)
\end{array}\right)
$$

These results are not analysed in Andersen (2005). Let us study the sign of the three variables. In particular, the sign of these variables is the opposite of the previous case when $\frac{\vartheta}{\left(\lambda_{h}\left(1-\mu_{h}\right)+\lambda_{f} \frac{r}{1+r}\right)}>-\left(\frac{\partial c\left(i_{k}^{*}, m\right)}{\partial m}\right)$ (i.e. the increasing in the taxation of the foreign region cover the decreasing migration costs). In this case $\frac{\partial t_{h}^{s}}{\partial m}>0, \frac{\partial s_{h}}{\partial m}>0$ if 
$\left(\frac{2}{(2+r)}-(1+r) \mu_{h}\right) \lambda_{h}<1$ and $\frac{\partial t_{h}^{u}}{\partial m}<0$ if $\mu_{h}<\frac{1}{(1+r)}$. Otherwise, the sign is the same found before an the difference is on the amount of these variations (all are lower than the previous case because the tax policies of $f$ absorb part of the effect of lower barriers to migration).

\section{THREE REGIONS' MARKET EQUILIBRIUM}

In this section we extend our analysis by assuming the existence of three regions ${ }^{8}$ Let us introduce a new region $f f$ that, given same conditions (see below) is able to attract skilled from region $f$.

Let us analyse the migration flow between region $f$ and $f f$. Higher is the labour productivity of the skilled work and lower is the rate of tax on their wage, higher is the quota of skilled which will migrate. Analysing the European data we find strong difference between UE and we can distinguish between two groups of European regions with higher and lower productivity .

Rewriting equation (2) we identifies three possible migration scenarios when

$t_{f f}^{s}>,=o r<\frac{w_{f}^{s}}{w_{f f}^{s}} t_{f}^{s}+\frac{w_{f f}^{s}-w_{f}^{s}}{w_{f f}^{s}}+\frac{1}{w_{f f}^{s}} c\left(i_{f f}^{*}, m\right)$

In the first case region $f$ attract skilled workers from region $f f$, in the second case there is not migration between the two regions, in the third case is the region $f f$ the pure receiving country. The second case implies the same results seen in the previous section with two only two regions. The first and third case are symmetric, so we study only the third case and we will extend the results to the first one. Let us assume, to simplify the analysis, that the skilled from region $h$ migrate only in region $f$. In this way, it is possible assume that both receiving country invest in migration policies (for simplicity the same investment $m$ ) and so compare the solutions of the three region's case to the ones of the two region's case.

According the previous sections, the labour market equilibrium is the same for the sending region, is $L_{f}^{s}\left(w_{f}^{s}, w_{f}^{u}, x\right)=\left(1-\mu_{k}\right) \lambda_{k}+\left(1-\mu_{f}\right) \lambda_{f}$ for the sending and receiving country, $L_{f f}^{s}\left(w_{f f}^{s}, w_{f f}^{u}, x\right)=\lambda_{f}+\left(1-\mu_{f}\right) \lambda_{f} \quad$ for $\quad$ the pure receiving region and $L_{k}^{u}\left(w_{k}^{s}, w_{k}^{u}, x\right)=2\left(1-\lambda_{k}\right)$, with $k=h, f$ and $f f$.

\footnotetext{
${ }^{8}$ Also in this case, we can extend the analysis on the study of three groups of regions.

${ }^{9}$ Labour costs in 2006 varied by one to twenty in the EU27. Expressed in euro, the average hourly labour costs in the EU27 in 2006 was euro 20.35. Sweden (e32.16) had the highest hourly labour cost in 2006, followed by Denmark (e31.98 in 2005), Luxembourg (e31.98) and Belgium (e31.58). Bulgaria (e1.65), Romania (e2.68), Latvia (e3.41) and Lithuania (e4.21) had the lowest. Within the structure of the labour costs, the highest share of social security costs paid by the employer was found in Sweden (30.6\%), followed by Belgium (30.3\%) and France (28.6\%) and the lowest shares in Malta (6.9\%), Denmark (10.9\%), Slovenia (13.4\%) and Cyprus (15.1\%). (Eurostat Yearbook 2008).
} 
According the previous sections, we study the condition to have in region $h, f$ and $f f$, unchanged education and migration incentives when the barriers to migrate decrease.

First, let us analyse the pure sending country $h$, the conditions are the same identified in equation (10).

Second, let us analyse the sending and receiving country $f$.

$$
\left\{\begin{array}{l}
\frac{\partial t_{f}^{s}}{\partial m}=\frac{w_{f f}^{s}}{w_{f}^{s}}\left(\frac{\partial t_{f f}^{s}}{\partial m}\right)+\frac{1}{w_{f}^{s}}\left(\frac{\partial c\left(i_{f}^{*}, m\right)}{\partial m}\right) \\
\frac{\partial s_{f}}{\partial m}=\left(\frac{\left(1-(2+r)\left(\lambda_{h}\left(1-\mu_{h}\right)+\frac{(1+r) \mu_{f}-1}{1+r} \lambda_{f}\right)\right)\left(w_{f f}^{s}\left(\frac{\partial t_{f f}^{s}}{\partial m}\right)+\left(\frac{\partial c\left(i_{f}^{*}, m\right)}{\partial m}\right)\right)-(2+r) \vartheta}{(1+r)\left(2(1+r)-r \lambda_{h}\right)}\right) \\
\left.\frac{\partial t_{f}^{u}}{\partial m}=\frac{(1+r)\left(\lambda_{h}\left(1-\mu_{h}\right)+\frac{(1+r) \mu_{f}-1}{1+r} \lambda_{f}\right)\left(w_{f f}^{s}\left(\frac{\partial t_{f f}^{s}}{\partial m}\right)+\left(\frac{\partial c\left(i_{f}^{*}, m\right)}{\partial m}\right)\right)+(1+r) \vartheta}{\left(\left(2(1+r)-r \lambda_{h}\right)\right) w_{f}^{u}}\right)
\end{array}\right.
$$

Third, let us analyse the pure receiving country ff.

$$
\left\{\begin{array}{l}
\frac{\partial t_{f f}^{u}}{\partial m}=\frac{w_{f f}^{s}\left(\lambda_{f}\left(1-\mu_{f}\right)+\lambda_{f f} \frac{r}{1+r}\right)\left(\frac{\partial t_{f f}^{s}}{\partial m}\right)+\vartheta}{w_{f f}^{u}\left(2+\frac{r \lambda_{f f}}{1+r}\right)} \\
\frac{\partial s_{f f}}{\partial m}=\frac{w_{f f}^{s}}{1+r}\left(\frac{\partial t_{f}^{s}}{\partial m}\right)-\frac{(2+r) w_{f f}^{u}}{1+r}\left(\frac{\partial t_{f f}^{u}}{\partial m}\right)
\end{array}\right.
$$

Also in this case, we can study two possible scenario: a) Government of $f f$ does not change the tax to educated; b) Government of $f f$ does not change the tax to non-educated.

Scenario a (migration and fiscal policies) $\frac{\partial t_{f f}^{s}}{\partial m}=0$.

In the first case, by the equation (20), implies that 


$$
\left\{\begin{array}{l}
\frac{\partial t_{f f}^{s}}{\partial m}=0 \\
\frac{\partial t_{f f}^{u}}{\partial m}=\frac{\vartheta}{w_{f f}^{u}\left(2+\frac{r \lambda_{f f}}{1+r}\right)}>0 \\
\frac{\partial s_{f f}}{\partial m}=-\frac{(2+r) w_{f f}^{u}}{1+r}\left(\frac{\partial t_{f f}^{u}}{\partial m}\right)<0
\end{array}\right.
$$

The same results and comments analysed in equation (14).

Let us study in this scenario the region $f$ by studying the system (19)

$$
\left\{\begin{array}{l}
\frac{\partial t_{f}^{s}}{\partial m}=\frac{1}{w_{f}^{s}}\left(\frac{\partial c\left(i_{f}^{*}, m\right)}{\partial m}\right)<0 \\
\frac{\partial s_{f}}{\partial m}=\left(\frac{\left(1-(2+r)\left(\lambda_{h}\left(1-\mu_{h}\right)+\frac{(1+r) \mu_{f}-1}{1+r} \lambda_{f}\right)\right)\left(\frac{\partial c\left(i_{f}^{*}, m\right)}{\partial m}\right)-(2+r) \vartheta}{(1+r)\left(2(1+r)-r \lambda_{h}\right)}\right) \\
\frac{\partial t_{f}^{u}}{\partial m}=\frac{(1+r)\left(\lambda_{h}\left(1-\mu_{h}\right)+\frac{(1+r) \mu_{f}-1}{1+r} \lambda_{f}\right)\left(\frac{\partial c\left(i_{f}^{*}, m\right)}{\partial m}\right)+(1+r) \vartheta}{\left(\left(2(1+r)-r \lambda_{h}\right)\right) w_{f}^{u}}
\end{array}\right.
$$

By definition, $\frac{\partial c\left(i_{k}^{*}, m\right)}{\partial m}<0$ then $\frac{\partial t_{f}^{s}}{\partial m}<0$. The receiving and sending region $f$, in order to compensate lower barriers to migration, has to decreasing the taxation of skilled workers.

Furthermore, the sign of the provision of the public good education is given by $\left(1-(2+r)\left(\lambda_{h}\left(1-\mu_{h}\right)+\frac{(1+r) \mu_{f}-1}{1+r} \lambda_{f}\right)\right)$.

In particular, if $\left(\lambda_{h}\left(1-\mu_{h}\right)+\mu_{f} \lambda_{f}\right)<\frac{1+(2+r)}{1+r} \lambda_{f}$ (i.e. the net level of skilled in $f$ (migrated and native) is very low) then lower barriers to migration imply $\frac{\partial s_{f}}{\partial m}<0$. 
Finally, the sign of the tax to unskilled is given by $\left(\lambda_{h}\left(1-\mu_{h}\right)+\frac{(1+r) \mu_{f}-1}{1+r} \lambda_{f}\right)$. In particular, if $\left(\left(\lambda_{h}\left(1-\mu_{h}\right)+\mu_{f} \lambda_{f}\right)<\frac{1}{1+r} \lambda_{f}\right)$ (i.e. the net level of skilled in $f$ (migrated and native) is lower than the quota of skilled born in $f$ ) then lower barriers to migration imply that $\frac{\partial t_{h}^{u}}{\partial m}>0$. Also in this case, note that the more costly it is to acquire education (the higher $r$ ), the worse is the redistribution of resource to the unskilled.

Let us study in this scenario the region $h$ by studying the system (10)

$$
\left\{\begin{array}{l}
\frac{\partial t_{h}^{s}}{\partial m}=\frac{1}{w_{h}^{s}} \frac{1}{w_{f}^{s}}\left(\frac{\partial c\left(i_{f}^{*}, m\right)}{\partial m}\right)+\frac{1}{w_{h}^{s}}\left(\frac{\partial c\left(i_{h}^{*}, m\right)}{\partial m}\right)<0 \\
\frac{\partial s_{h}}{\partial m}=\frac{1}{1+r}\left(1-\frac{(2+r)\left(1-(1+r) \mu_{h}\right) \lambda_{h}}{\left(2(1+r)-r \lambda_{h}\right)}\right)\left(\frac{1}{w_{f}^{s}}\left(\frac{\partial c\left(i_{f}^{*}, m\right)}{\partial m}\right)+\frac{\partial c\left(i_{h}^{*}, m\right)}{\partial m}\right) \\
\frac{\partial t_{h}^{u}}{\partial m}=\frac{\lambda_{h}\left(1-(1+r) \mu_{h}\right)}{\left(2(1+r)-r \lambda_{h}\right)} \frac{1}{w_{h}^{u}}\left(\frac{1}{w_{f}^{s}}\left(\frac{\partial c\left(i_{f}^{*}, m\right)}{\partial m}\right)+\left(\frac{\partial c\left(i_{k}^{*}, m\right)}{\partial m}\right)\right)
\end{array}\right.
$$

Analysing the sign of the variables, we derive that $\frac{\partial t_{h}^{s}}{\partial m}<0, \frac{\partial s_{h}}{\partial m}>0$ if $\left(\frac{2}{(2+r)}-(1+r) \mu_{h}\right) \lambda_{h}>1$ and $\frac{\partial t_{h}^{u}}{\partial m}<0$ if $\mu_{h}<\frac{1}{(1+r)}$.

Scenario b (fiscal and migration policies with redistributive constraints) $\frac{\partial t_{f f}^{u}}{\partial m}=0$.

In this scenario the results are similar to those analysed in the previous section, let us so compare only the difference in the tax to skilled.

$$
\frac{\partial t_{f f}^{s}}{\partial m}=\frac{\vartheta}{w_{f f}^{s}\left(\lambda_{f}\left(1-\mu_{f}\right)+\lambda_{f f} \frac{r}{1+r}\right)}>0
$$

The government of $f f$ compensates the increasing cost in migration policies by increasing the taxation of .skilled and by increasing the provision of public education. In particular, higher is the quota of skilled workers in $f f$ (natives and foreign), lower is the increasing in the skilled taxation and the increasing of publicly education. 
$\frac{\partial t_{f}^{s}}{\partial m}=\frac{1}{w_{f}^{s}}\left(\frac{\vartheta}{\left(\lambda_{f}\left(1-\mu_{f}\right)+\lambda_{f f} \frac{r}{1+r}\right)}\right)+\frac{1}{w_{f}^{s}}\left(\frac{\partial c\left(i_{f}^{*}, m\right)}{\partial m}\right)$

The sign of these variables is the opposite of the previous case when $\left(\frac{\vartheta}{\left(\lambda_{f}\left(1-\mu_{f}\right)+\lambda_{f f} \frac{r}{1+r}\right)}\right)>-\left(\frac{\partial c\left(i_{f}^{*}, m\right)}{\partial m}\right)$ (i.e. the increasing in the taxation of the foreign region cover the decreasing migration costs) In this case $\frac{\partial t_{f}^{s}}{\partial m}>0$.

$\frac{\partial t_{h}^{s}}{\partial m}=\frac{1}{w_{k}^{s}}\left(\left(\frac{\vartheta}{\left(\lambda_{f}\left(1-\mu_{f}\right)+\lambda_{f f} \frac{r}{1+r}\right)}\right)+\frac{1}{w_{f}^{s}}\left(\frac{\partial c\left(i_{f}^{*}, m\right)}{\partial m}\right)\right)+\frac{1}{w_{k}^{s}}\left(\frac{\partial c\left(i_{k}^{*}, m\right)}{\partial m}\right)$

\section{CONCLUSIONS}

Analysing the BD in EU, we discover that we have a bi-directional phenomenon. From one side the EU suffer strong "drain" of his scientist and from the other side the EU is an important "pole of attraction" of the BD from several LDCs and from the other European countries. To analyse this duality of the European BD, we presented two different specification of a simple theoretical model.

In the first specification we analysed the first characteristic of the European BD: the simultaneous presence of regions which attract skilled (i.e. former EU, $f$ in the model) and of regions which provide skilled (i.e. new EU's entrants, $h$ in the model). The solutions of this analysis is summarized in the table (1) which shows the policies that the two regions will implement in order to maintain educational incentives without leading to more emigration when mobility costs become lower by migration policies of the sending country.

\section{[HERE TABLE 1]}

In particular, equations (14) and (15) analyse the case in which the sending region invest more resources in order to attract skilled. Because the tax rate on skilled of $f$ does not change (i.e. the resources for these policies derive from higher taxation to unskilled and lower investment in education) we define this scenario the migration competition one. In this case the sending country, in order to sterilize the migration policies of $f$ is forced to decrease the tax rate on skilled (in order to increase the incentives to stay at home) and to implement a combination of lower taxation of skilled workers and reduced educational subsidies. Only if the region $h$ has sufficient resources to maintain educational incentives without leading to more emigration when mobility costs become lower then will be a scenario where in both regions the increasing mobility implies low redistribution of income 
and lower investment in education. According to the literature, we assist to an increasing in the taxation of the immobile factor and a decreasing of the mobile one. On the contrary, when the sending region is not more able to contrast the migration policies of $f$, then the market will move to a new equilibrium where the receiving region gains from new flows of skilled (and repays the investment in migration policies) and the sending region is forced to reduce more the redistributive policies and the investment in education because it is not able to capture an increasing part of these investments.

Furthermore, equations (16) and (17) analyse the case in which the sending region invest more resources in order to attract skilled but do not change the taxation on unskilled. This case is equivalent to assume that these region is forced to maintain a given level of investment in education (i.e. the European Commission define a minimum level of investment in R\&D for the receiving country). Consequently, to cover the new expenses on migration policies the region $f$ is forced to increase the level of taxation on skilled and, to maintain unchanged the incentives to education, to increase the investment in education. We define this the migration competition with redistributive constraints scenario. Also in this case the sending country, in order to sterilize the migration policies of $f$ is forced to decrease the tax rate on skilled and implement a combination of lower taxation of skilled workers and reduced educational subsidies as before but less than the case without educational investment constraints. This second scenario capture $s$ the positive impact of the presence of a Central Authority which impose a minimum level of provision of the public good education of the receiving country.

In the second specification of the model, we analyse the second characteristic of the European BD, the presence of regions which are simultaneously receiving (by attracting skilled, $f$ in the model) and sending countries (attracted by higher productive regions i.e. the U.S.A., $f f$ in the model) and regions which are pure sending countries $(h)$. Both the receiving countries ( $f$ and $f f$ ) could increase, by investing resources, the level of integration between countries and to reduce the level of migration costs. The solutions of this analysis is summarized in the table (2) which compares the skilled's taxation policies that the three regions will implement in order to maintain educational incentives without leading to more emigration when mobility costs become lower by migration policies of both sending countries.

\section{[HERE TABLE 2]}

In particular, the first column compares the migration competition scenario analysed in the two regions' model with the migration and fiscal competition scenario analysed in the three regions' model. The presence of a new "pure receiving" country which is able to implement migration policies to attract skilled form $f$ obligates this one to sterilize the $f f$ migration policies by invest itself into new migration policies (in order to attract skilled from $h$ ) and to decrease the tax rate on skilled (in order to sterilize the lower barriers to migrate). The combination of these policies (migration and fiscal) increase the final effect on the pure sending country $h$ which must reduce the skilled's tax more than $f$ in order to sterilize both migration policies of $f$ and $f f$ and the fiscal policies of $f$. As in the previous case, the final result for who looses skilled workers are lower investment in education and lower redistributive policies. 
Moreover, the second column compares the migration competition with redistributive constraints scenario analysed in the two regions' model with the migration with redistributive constraints scenario analysed in the three regions' model. As in the previous case, the final result for who loose skilled workers are lower investment in education and lower redistributive policies.

In both scenarios, the key element is the possibility for the higher productivity regions to implement migration policies in order to increase the flow of skilled workers attracted. These policies imply the investment of resources which are moved from redistributive policies and from the educational investments. Furthermore, each "Brain attractor" my be tempted to adopt free riding behaviour by decreasing the investment in education of the native agents and by attracting more skilled workers educated abroad by invest in $m$. In our model, this possibility is clearly captured by the result showed in the first column of Table 1. Moreover, we analysed the model at equilibrium by assuming that the sending region is able to implement policies that guarantee unchanged migration and educational decisions. When $h$ has not sufficient resources to sterilized longer these migration and fiscal policies, then this one is forced to follow the same "auto destructive mechanism" started by $f$, to decrease the skilled's taxation and to continue the "rice to bottom" in the provision of the public education. This dangerous effect is well know from EU institutions which suggested to define a target in the investment in education and research, the Lisbon Strategy. In particular, the subsequent Spring European Councils (Lisbon 2000, Stockholm 2001, Barcelona 2002 and Brussels in 2003) agreed that overall spending on R\&D in the Union should be increased with the aim of approaching 3\% of GDP by 2010 . Moreover, only Finland and Sweden have reached this goal. For the whole union to hit the target by 2010, R\&D investment must grow by $8 \%$ a year, nearly twice the $4.5 \%$ annual increase recorded since 1997 (COM 2001a, COM 2001b and COM 2003).

To capture the impact of the EU area of the minimum target of investment in research, we analysed (see the second column of the Table 1) the case in which the receiving country does not change their redistributive policies. This assumption implies that the receiving country is forced to subsidy the migration policies by augmenting the taxation to educated and (to maintain unchanged the educational incentives) to increase the level of publicly education. In this way the minimum level of investment in R\&D can be assured. Let us note that the increment of educational subsidies could be used as instrument of migration competition. In exemplum Portugal has increased the number of mobility fellowships for incoming foreign researchers by 50\% from 1994 to 1999. Finland has bilateral research exchange schemes with many of the candidate countries. Almost $50 \%$ of Luxembourg's national research grants are allocated to non-nationals. Finally Germany, UK, France, Netherlands and Denmark have research grants and fellowships for increase the presence of non national researchers .

Furthermore, the second specification of the model help us to capture better the migration competition phenomenon inside the EU by assuming that both the receiving countries $(f$ and $f f$ in the model) implement uncoordinated migration policies in order to increase the flow of skilled migrated from $h$. Also $\mathrm{n}$ this case, free riding behaviours of the receiving countries may start a perverse migration competition in order to attract more and more skilled as substitute of the native skilled which require investment in education to be created. This result is captured by the model solutions (see Table 2), where the region $f$ 
decrease the level of taxation to educated and consequently decrease the amount of resources invested to subsidy the education. There are several examples of countries that providing tax reductions specifically for researchers: Denmark, Sweden, Netherlands and France. In particular, Denmark and Sweden outstanding researcher tax reduction for up 3 years from $40 \%$ to $25 \%$, moreover, in Netherlands, speciality workers compensated with a rebate of $30 \%$ of total earned during stay. Other countries, like Austria and UK, provide different policies for highly skilled specialist. Furthermore, a recent a study carried out for the French Senate tells of a "discouraging landscape of administrative convolution, heavy taxes and inflexible labour legislation". The negative part for the sending countries of this migration policies is increased by the fact that these ones are uncoordinated between the receiving countries. The impact of this migration competition is showed in the model solutions (Table 2) by the presence two decreasing in the migration costs that the sending regions have to sterilize. Examples of migration policies as answer to other similar policies are several. For example, France in 2004 introduced tax deductions for highly skilled migrants and this reform was explicitly motivated by the fact that Belgium had adopted policies encouraging inflows of highly skilled workers; similarly, the British ad hoc scheme for highly skilled migrants was motivated referring to the measures being taken in Germany, etc. Furthermore, this specific competition in migration policies was also evident when the EU-15 adjusted their regulations on work permits in the eve of the Eastern Enlargement. Furthermore, some countries implement marketing and recruiting policies directly oriented to attract foreign researchers by compete to other regions. For exemplum, in some countries, such as France, the Netherlands, Finland and the UK, there are nationwide integrated Internet sites on opportunities and regulations. In France, the Kastler Foundation provides personalised assistance to researchers from abroad. Though not always a requirement, it is common practise in many Member States to publish research vacancies internationally. In the UK, open recruitment is common practice with some schemes supporting the costs of recruiting outstanding researchers from industry or overseas. In some research funding organisations in Member States (e.g. Portugal, Finland, Sweden), foreign participation in recruitment and/or evaluation committees is compulsory or facilitated by requiring applications to be written in a 'world' language. The Department for Education and Employment launched the UK Education Brand which marked the beginning of a three-year programme to raise the profile overseas of UK education. The Brand, together with generic marketing materials, supports promotion activities overseas of UK higher education institutions. The budget put towards this initiative is 7.8 million EUR. Furthermore, an example of policy studied for the return of migrants to their source country is the so called "Irish Christmas recruitment". The Irish Ministers of Enterprise Trade and Development are recruiting expatriates to return to build the software industry; targeting those returning home for Christmas. In France and Finland there is a unified body for the international marketing. In Italy, the Government is trying to turn the Brain Drain into a gain. The so-called operation 'Brain Buster', launched by the MIUR aimed to attract back Italian scientists and/or foreign academics working in the research sector abroad. Finally, some of these policies of recruiting are specifically devoted to the former eastern bloc countries. In exemplum, Germany, Austria and France are actively recruiting undergraduate and post-graduate science students from Poland and other former eastern bloc countries. First indications suggest that Germany and Austria are now the top choice for many of the brightest foreign students, who are being offered incentives such as university courses in English and favourable funding schemes. 
Concluding this article, data show that in EU there exist bi-directional flow of skilled migrants and differences in the labour productivity between regions. These two elements implies that the receiving and the sending and receiving countries implement several migration policies in order to increase their capacity to be a pole of attraction for the skilled workers. In many case these policies implied a "migration competition" between the receiving countries which attract the skilled from the same basin (i.e. the Eastern countries). In this article, we replicate these dynamics and, according to the economics literature, we demonstrate that these migration policies and this migration competition imply a worst equilibrium in which there is lower redistribution and lower provision of the public good education. Furthermore, in both versions of the model, we demonstrate that the introduction of a central authority, which stop the "rice to bottom" in the provision of subsidies to education by target a minimum level of $\mathrm{R} \& \mathrm{D}$, may reduce or block some negative impact of these policies both in the sending both in the receiving country. This result is in line to the Lisbon strategy proposed by the EU Commission. Finally, we show another crucial role for the EU. In the second specification of the model, we introduce the necessity that the EU coordinates these migration policies in order to avoid the possible negative effects of the "migration competition" inside the Union, but, until now, there is not tentative to coordinate these migration policies.

\section{REFERENCES}

Andersen, T. M. (2005), Migration, taxation and educational incentives, Economics Letters 87 399-405.

COM (2001a) -High level expert group on Improving mobility of researchers. European Commission - Directorate general research - Brussels.

COM (2001b) Final Communication From The Commission To The Council And The European Parliament- A Mobility Strategy For The European Research Area Commission Of The European Communities - Brussels.

COM (2003) Communication from the commission to the council and the European parliament - Researchers in the European research area: one profession, multiple careers- Commission of the European Communities- Brussels.

Eurostat yearbook (2008), Europe in figures, Eurostat, European Commission. Luxembourg: Office for Official Publications of the European Communities, 2008.

OECD (2004), Education at a Glance, 2004 edition. 


\section{TABLE 1}

\section{TWO REGIONS}

Sending Region $\mathbf{h}$

Receiving Region $\mathrm{f}$

Migration Competition

$$
\left\{\begin{array}{l}
\frac{\partial t_{h}^{s}}{\partial m}=\frac{1}{w_{k}^{s}}\left(\frac{\partial c\left(i_{k}^{*}, m\right)}{\partial m}\right)<0 \\
\frac{\partial s_{h}}{\partial m}=\frac{1}{1+r}\left(1-\frac{(2+r)\left(1-(1+r) \mu_{h}\right) \lambda_{h}}{\left(2(1+r)-r \lambda_{h}\right)}\right)\left(\frac{\partial c\left(i_{k}^{*}, m\right)}{\partial m}\right) \\
\frac{\partial t_{h}^{u}}{\partial m}=\frac{\lambda_{h}\left(1-(1+r) \mu_{h}\right)}{\left(2(1+r)-r \lambda_{h}\right)} \frac{1}{w_{h}^{u}}\left(\frac{\partial c\left(i_{k}^{*}, m\right)}{\partial m}\right)
\end{array}\right.
$$

$$
\left\{\begin{array}{c}
\frac{\partial t_{f}^{s}}{\partial m}=0 \\
\frac{\partial t_{f}^{u}}{\partial m}=\frac{\vartheta}{w_{f}^{u}\left(2+\frac{r \lambda_{f}}{1+r}\right)}>0 \\
\frac{\partial s_{f}}{\partial m}=-\frac{(2+r)}{2(1+r) r \lambda_{f}} \vartheta<0 \\
\text { equation }(14)
\end{array}\right.
$$

\section{Migration Competition with redistributive constraints}

$$
\left\{\begin{array}{l}
\frac{\partial t_{h}^{s}}{\partial m}=\frac{1}{w_{k}^{s}} \frac{\vartheta}{\left(\lambda_{h}\left(1-\mu_{h}\right)+\lambda_{f} \frac{r}{1+r}\right)}+\frac{1}{w_{k}^{s}}\left(\frac{\partial c\left(i_{k}^{*}, m\right)}{\partial m}\right) \\
\frac{\partial s_{h}}{\partial m}=\frac{1}{1+r}\left(1-\frac{(2+r)\left(1-(1+r) \mu_{h}\right) \lambda_{h}}{\left(2(1+r)-r \lambda_{h}\right)}\right)\left(\frac{\vartheta}{\left(\lambda_{h}\left(1-\mu_{h}\right)+\lambda_{f} \frac{r}{1+r}\right)}+\frac{\partial c\left(i_{k}^{*}, m\right)}{\partial m}\right)
\end{array}\right.
$$$$
\frac{\partial t_{h}^{u}}{\partial m}=\frac{\lambda_{h}\left(1-(1+r) \mu_{h}\right)}{\left(2(1+r)-r \lambda_{h}\right)} \frac{1}{w_{h}^{u}}\left(\left(\frac{\vartheta}{\left(\lambda_{h}\left(1-\mu_{h}\right)+\lambda_{f} \frac{r}{1+r}\right)}\right)+\left(\frac{\partial c\left(i_{k}^{*}, m\right)}{\partial m}\right)\right)
$$

$$
\left\{\begin{array}{c}
\frac{\partial t_{f}^{s}}{\partial m}=\frac{\vartheta}{w_{f}^{s}\left(\lambda_{h}\left(1-\mu_{h}\right)+\lambda_{f} \frac{r}{1+r}\right)}>0 \\
\frac{\partial t_{f}^{u}}{\partial m}=0 \\
\frac{\partial s_{f}}{\partial m}=\frac{\vartheta}{\left((1+r) \lambda_{h}\left(1-\mu_{h}\right)+r \lambda_{f}\right)}>0 \\
\text { equation (16) }
\end{array}\right.
$$$$
\text { equation (17) }
$$ 
TABLE 2

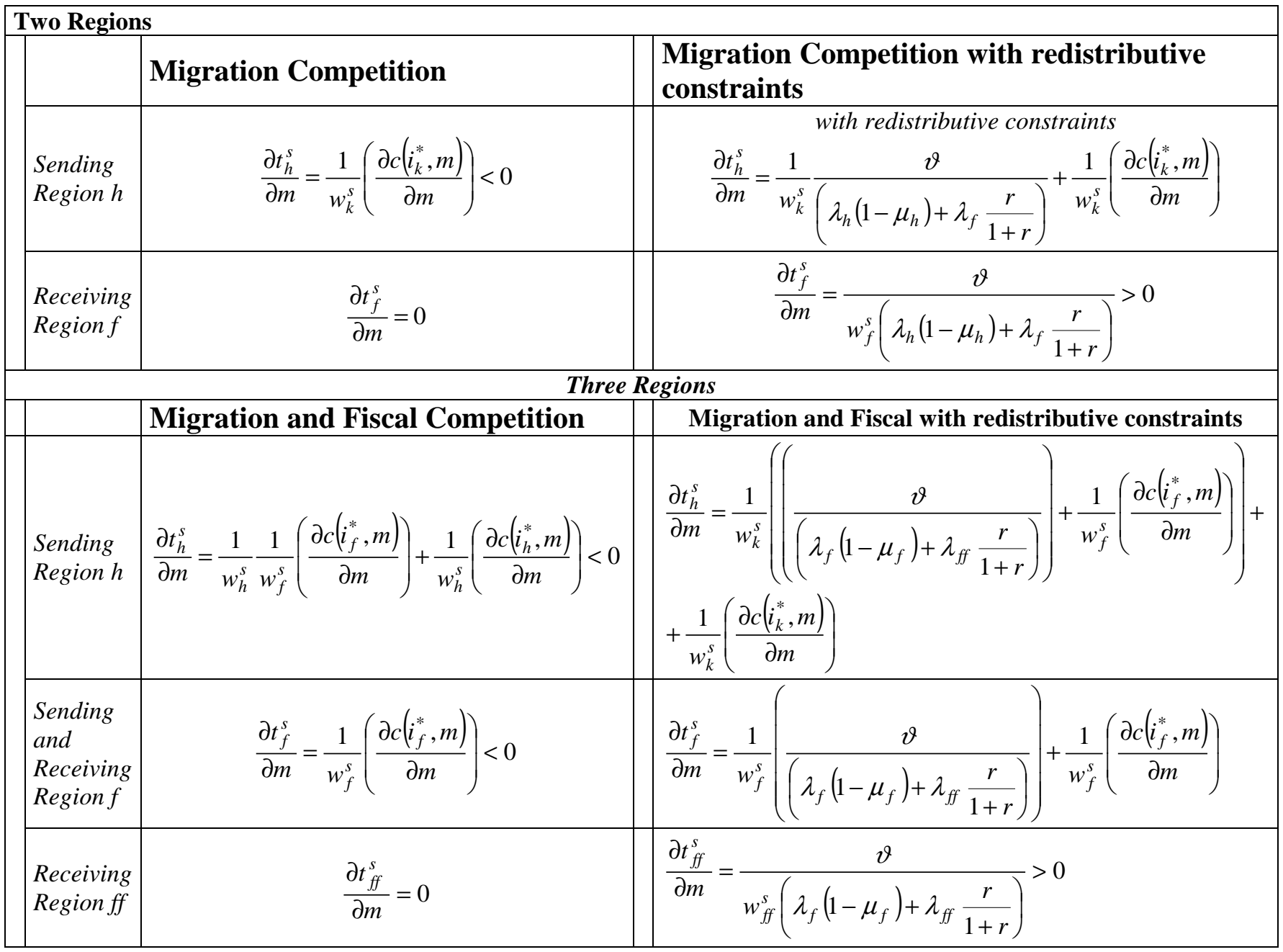

22 